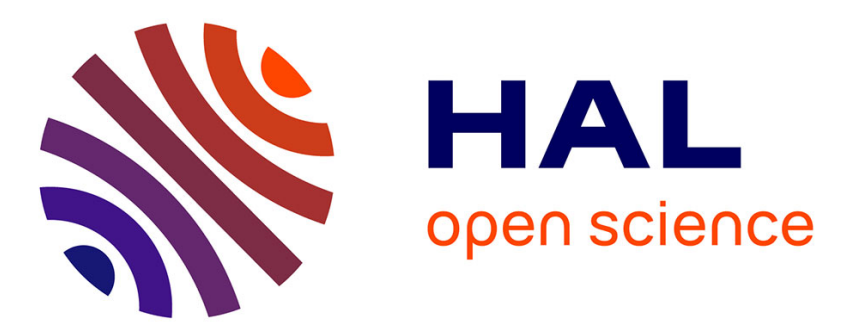

\title{
An Organizational Model to Understand the Creativity Workshop
}

Pedro Chávez Barrios, Davy Monticolo, Sahbi Sidhom, Alex Gabriel

\section{To cite this version:}

Pedro Chávez Barrios, Davy Monticolo, Sahbi Sidhom, Alex Gabriel. An Organizational Model to Understand the Creativity Workshop. SITIS - The 13th International Conference on SIGNAL IMAGE TECHNOLOGY \& INTERNET BASED SYSTEMS, Dec 2017, Jaipur, India, India. 10.1109/SITIS.2017.87 . hal-01713737

\section{HAL Id: hal-01713737 \\ https://hal.inria.fr/hal-01713737}

Submitted on 20 Feb 2018

HAL is a multi-disciplinary open access archive for the deposit and dissemination of scientific research documents, whether they are published or not. The documents may come from teaching and research institutions in France or abroad, or from public or private research centers.
L'archive ouverte pluridisciplinaire HAL, est destinée au dépôt et à la diffusion de documents scientifiques de niveau recherche, publiés ou non, émanant des établissements d'enseignement et de recherche français ou étrangers, des laboratoires publics ou privés. 


\section{An Organizational Model to Understand the Creativity Workshop}

\author{
Pedro Chávez Barrios \\ ERPI Laboratory, University of Lorraine \\ 8 rue Sebastian Lepage, 54000 Nancy, France \\ pedro.chavez-barrios@univ-lorraine.fr
}

\author{
Davy Monticolo \\ ERPI Laboratory, University of Lorraine \\ 8 rue Sebastian Lepage, 54000 Nancy, France \\ davy.monticolo@univ-lorraine.fr
}

\author{
Sahbi Sidhom \\ LORIA(Kiwi) Laboratory, University of Lorraine \\ F-54506 Vandouvre lès Nancy, France \\ sahbi.sidhom@loria.fr \\ Alex Gabriel \\ ERPI Laboratory, University of Lorraine \\ 8 rue Sebastian Lepage, 54000 Nancy, France \\ alex.gabriel@univ-lorraine.fr
}

\begin{abstract}
There are a great interest in developing and using creativity in our society. We observe that industry and educative centers organize creativity workshops in order to solve problems. Creativity workshops have primordial elements such as creative solvers, creative supporters, and some activities to generate ideas. Their objectives are to apply creativity methods to generate ideas. The ideas generation process is a collaborative process among different activities (ideas creation, clustering, evaluation, etc.) and among participants which have different roles, point of view and experiences. We consider each activity as an organization where participants work together to achieve a common goal which is the idea generation. We propose in this paper to use an organizational approach to model the idea management process from the interaction among the roles during all the creativity activities.
\end{abstract}

Keywords-component; KROM; creativity workshops; knowledge management;

\section{INTRODUCTION}

The aim of this article is to model a creative workshop to highlight knowledge, roles, the interaction among roles and the organizational creativity. To do this modeling we based our thought on a creativity workshop (CWS) called "48 hours to generate ideas" $(48 \mathrm{H})$ to solve industrial problems where participants use different rules, information sources, processes, creativity methods, and ways to generate ideas. The $48 \mathrm{H}$ is organized annually by the ENSGSI engineering school and the ERPI laboratory at the University of Lorraine in Nancy that also involve simultaneously some French universities, and universities from different places of the world working in a collaborative, organizational and international context. Since decades, this workshop implies students from various backgrounds and during 48 hours they generate many ideas in order to solve problems suggested by industrial.

The rules to participate are a) to be student or professor from any University, to be an industrial manager with a subject or problem, to be an industrial technician; b) to apply creativity methods; c) To generate a huge number of ideas. The sources of information are given by industrial managers, creative experts, facilitator, and some applications. There are different processes like a) to create collaborative groups, b) to collaborate and create ideas, and c) to show the physical representation of solutions. The creativity methods are huge because every creative expert has a method to advice to the group.

We observe creativity groups inside the $48 \mathrm{H}$ in order to understand what are the collaborative processes to generate ideas, how the participants share their know-how and knowledge. The aim objective is to design an intelligent system to help people to share their experience in order to create more ideas.

The principle of a creativity workshop (CWS) is to gather people that apply creativity methods in order to facilitate the generation of ideas and to solve open issues. If creativity is historically considered as an individual process, complex problem solving situation requires collective and collaborative creative process. "Team collaboration is particularly important under several circumstances such as in dynamic situations, for team adaptation, and when creativity is needed" [1]. Therefore, we can observe that creativity is the most important topic, ability, reason, generator during the $48 \mathrm{H}$ and has the purpose to solve industrial's problems. To generate a huge number of ideas, participants have to share knowledge. Our objective is to highlight the knowledge sharing inside the creativity collaborative process.

Our approach is to model knowledge by using a organizational meta model called KROM (Knowledge Reuse Organizational Meta-Model) which facilitates the understanding of the collaboration among roles and highlights knowledge by collaborative activities.

The document presents a model to understand the way that students, industry and educative centers work during a CWS like $48 \mathrm{H}$. In the, section 2 we describe the creative workshop $48 \mathrm{H}$ dedicated to solve problems and in section 3 we present the modeling of the creativity workshop by using KROM. 


\section{AN ORGANIZATIONAL MODEL TO HIGHLIGHT KNOWLEDGE DURING A CREATIVITY WORKSHOP}

The creativity workshop (CWS) called $48 \mathrm{H}$ has been an important event created by the ENSGSI. The last workshop was in November 2016. 1500 students from different places of the world applied creativity methods in a collaborative way and in an international context. The aim objective of the students is to solve a industrial problems.

To model the $48 \mathrm{H}$, we use the meta-model KROM [2]. This organizational model has three domains: description of organizational structure, description of expertise management, and description of knowledge management (figure 1). We follow these three descriptions in order to understand a collaborative CWS which is essential to help solver-participants to manage ideas, to apply creative techniques and sharing knowledge.

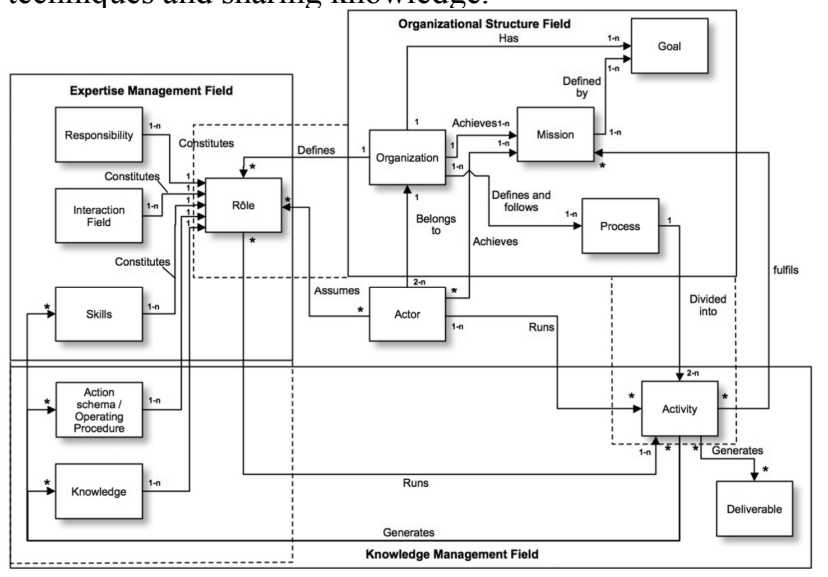

Figure 1. KROM Organizational Model.

The KROM organizational model aims to describe the human organizations. This model has been used to model human ophthalmic engineering organizations. It highlights the skills of the professional actors, the description of the knowledge that they create, use and share, and the formalization of the organizational structure that they enforce. The fundamental elements of KROM can be divided into three main descriptions:

- Description of organizational structure, a) Organization identity: defining missions and goals; b) Organization actions: defining the process (es) used.

- Description of expertise management: defining roles, responsibility, interaction fields, skills, Action schema and knowledge.

- Description of knowledge management: defining deliverable name, generated knowledge, generated, competence, generated action schema, and relations of leadership, alliance (same goals) and coalition (sharing information).

These descriptions help us to fill the model in three stages, first, we define the organizational structure (figure 2), after that, all processes and activities are detailed (figure 3 and 4) and finally roles are defined with missions, competences, knowledge, interaction fields and responsibilities. When the model applied is finished, two CWS are analyzed with respect to roles, country, technics, level of students, objectives, and days.

\section{MODELING THE CREATIVITY WORKSHOP BY USING ORGANIZATIONAL MODEL KROM}

In the creativity workshop $48 \mathrm{H}$, a new topic (problem to solve), is given to each creative group. After discovering the problem, the participants use different creativity ways to produce novel ideas:

- Combinational: new ideas are produced by combination among other ideas.

- Exploration: ideas with some rules.

- Transformation: ideas with some alteration, Boden [3].

After the problem discovery activity, a creative coach explains the different collaborative-creative methods to the participants and creates a trust atmosphere by using team building games. The trust in the creative groups is an important condition to facilitate the ideas creation.

At the organizational level, creativity is the creation of a valuable, useful product, service, idea, procedure, or process by individuals working together in a complex social system [4]. In order to reach this creation of value, stakeholders assume different roles as facilitator, organizer, creative expert, solver-participant during the workshop. Some of these roles create the required environment that permits to other roles to exchange ideas. These ideas are as knowledge that nurture the exploratory, combinational and transformational creativity of individuals located in the same place that are solving the problem [5], [6], [7]. "Organizational creativity is influenced by many things. Some are social others are brought to the organization by the individuals who comprise it. To a certain degree, then, organizational creativity depends on the abilities of the individuals within it" [8]. De facto, organize and execute a creative workshop require knowledge about the creative process, the context of the problem, the field of the problem, the individuals involved in order to permit to participants to solve the issue. The group of solver-participants has all the conditions to generate probably something new and unexpected. It is considered a desirable property and characteristic of intelligent human beings [9].

The participants achieve several creative sequences to generate a huge quantity of ideas. In the collaborative and creative method solver-participants formalize, describe, write and represent their ideas and idea cards by using sticky notes, paper boards, images, pictures, sounds and videos. An Idea Card is the result of a process of "collaboration and creation" which have several actions such as "meeting group", "collaborative and creative methods with individual and group activities", "To write Idea Cards", "To share Idea Cards" and "To select innovative ideas".

\section{A. The Organizational Structure}

The CWS " $48 \mathrm{H}$ " has two specific missions: to achieve and defines processes, and to follow them; these two missions rely on five processes and contribute by two goals; the figure 2 shows those relations. 


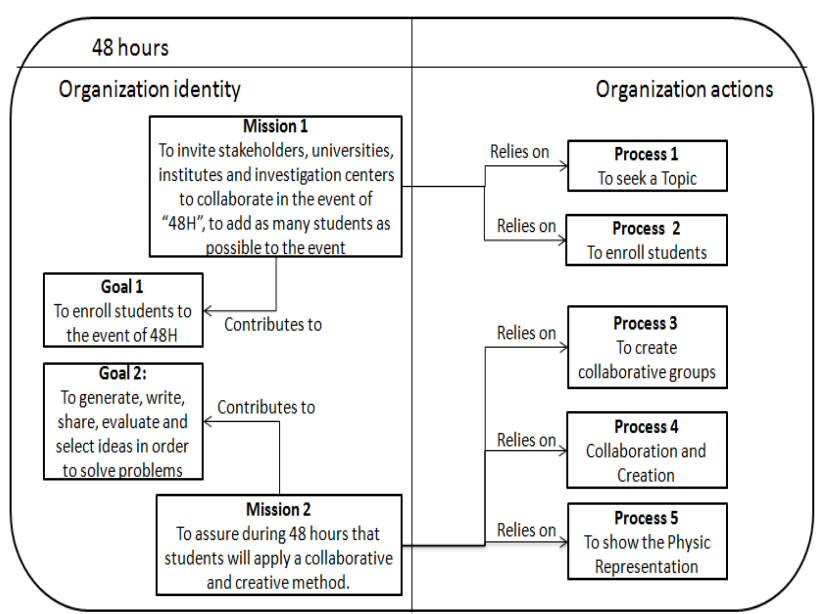

Figure 2. Organizational Structure.

\section{B. Processes and Activities}

In this section, we model the collaborative creative process (figure 3 ) which is defined with five activities, the first activity called "Domain discovery, Meeting group", second activity is "collaborative and creative methods, Individual and groupal activities", third activity is "to write idea cards", fourth activity is "to give advise" and finally the fifth activity called "Selecting innovative ideas".

Every activity has an input(s) and an output(s), as an example: in the first activity, the inputs are the topic and the group; the outputs are pictures, photos and small pieces of information, that outputs will be the input for the next activity. The outputs for second activity are sticky notes, paper board, images, picture, sound, video; these outputs will be the inputs for the next activity. The same idea will be for activities three, four and five; As a result of this process, we will have "the best idea-card".

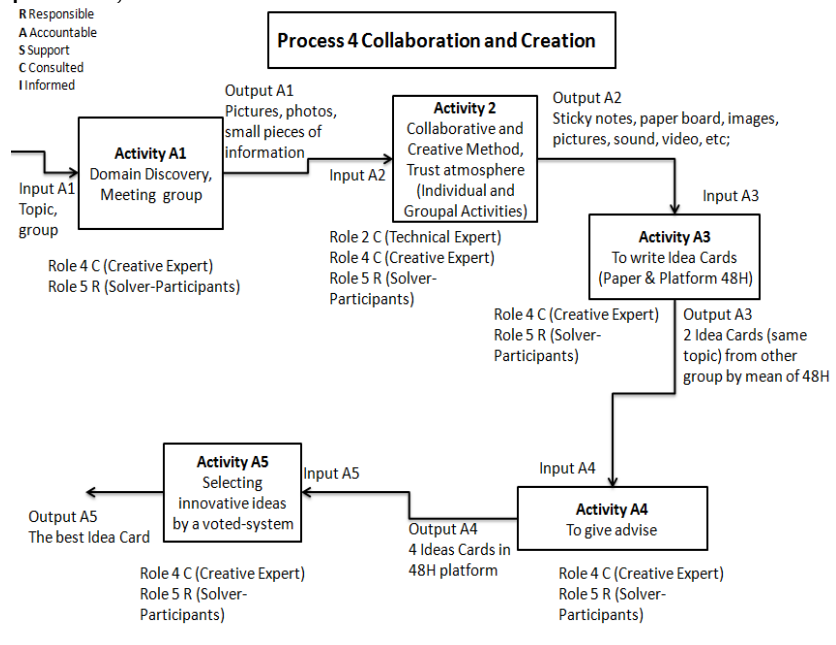

Figure 3. The Process of Collaboration and Creation.

In addition, every activity has the roles that will interact during the activity and also the characteristic of the role during the activity (Responsible, Accountable, Support, Consulted and Informed), as an example: in the activity 2, the solver-participant is responsible, the technical expert and creative expert are consulted.
Finally, in every activity the roles are working in a collaborative way, during the process, the team of solverparticipant is using creative methods to generate a lot of ideas and also work in individual and a group way to generate ideas. These ideas are writing in an idea-card format, after that, two ideas are selected by the group in order to share them to other teams. Every group score ideas, as a result of that, the best idea is selected.

The format of an idea-card, in this example (figure 4), it contains several fields in an heterogeneous formats similar to the Khemiri's idea who develop indexing and information retrieval (IR) processes based on noun phrase (NP) and its semantic representation [10]. It also offers us information about the country, city and institution where the format was created; In this example, the team is from Toulouse and show us the problem (Topic), there are too a description of the idea-card, a design that offers more details, the scenario shows a brief example about "how to use", the idea card also give us some advantages, risks and competences necessaries to get the solution. Below, a better explanation of each field:

The problem to solve is "suggestion of place", this problem's name gives us a general view, many teams will be focus on it;

The team "Toulouse équipe 10 " makes reference to a specific place; it could be the university, school, or city inside of the creativity workshop $48 \mathrm{H}$, and the consecutive number of team;

The topic shows us the global idea to solve the problem "Topic E Interconnected object" the interconexion between the subject and the object;

Detailed description has the most important function, it has to explain the way that the solution of the problem by mean of this specific idea-card, this solution has several sentences used by the authors in natural language: "The application would function on the principle of a an aggregator software. It will be possible to link the application account to social network accounts in order to customize the suggestions of the application: Depending on the places visited by yourself or other users of the application known by the ibeacon, this one sugests to you in passing near to another terminal ibeacon a place suceptible to interest you.", this description could have typographics or lexical errors since it is redacted by the solver participants.

Prioritary clients: "Young adultes (18-25) et Adultes (25-45)", the people's rank of age that might use this solution, it is clear that people who can cover two characteristics, control and use an application and the capacity to pay and to move among interesting places.

Way to use "Scenario of use", this field is similar in importance like the field description detailed, the way to use the solution offers a better understanding of the solution because it has some steps or a procedure to get the solution: "After having left a restaurant A if most of the users went to a bar B then a night club $\mathrm{C}$, the application will give you the address and the itinerary to these displacements. The application will remember your choice and personalize its future suggestions for you or other users".

Advantages: "Allows you to discover a new place", "Extend the clients of different bars, restaurants ..." and 
"Allows you to plan an evening in an unknown city", this field gives us some positive aspects of the solution.

Risks or disadvantages: "Loss of sense of discovery by the user", contrary to the prior field, this field describes the negative aspects of the solution.

Competences or skills required developing it "Software mastery", this field show us the skills required by the user to get the solution.

The field draw shows us a graphic way of the solution.

Suggestion of place
Team: Toulouse-team 10

Figure 4. The Idea Card.

An activity (figure 5), shows the roles used to achieve the generated knowledge, generated competence, generated action schema and deliverable name which are been obtained by three types of interactions: Alliance (the same goals), Coalition (share information) and Leadership (there is a leader role) [11].

This activity delivers four ideas and solver participant promotes the description of this idea in an idea card which contains knowledge such as number of idea, name of idea, knowledge_NeedProb, Number of knowledge, Description, Cibles, SchemaDesciption and scenario usage. Here, the most important knowledge is "Description" and also "SchemaDescription". The knowledge description will have important sentences, propositions and words that offer a solution for a specific problem. The knowledge schemaDescription shows a dessign about the solution, this draw give us many details about how the team has seen the problem and how they will be solved it.

There are two important actions in the role of solverparticipant, the first is "put attention and be collaborative" and the second "to participate in the videoconference feedback". With respect to the role creative-expert, the action schema is "to lead the group" but also "to be in the conference feedback".

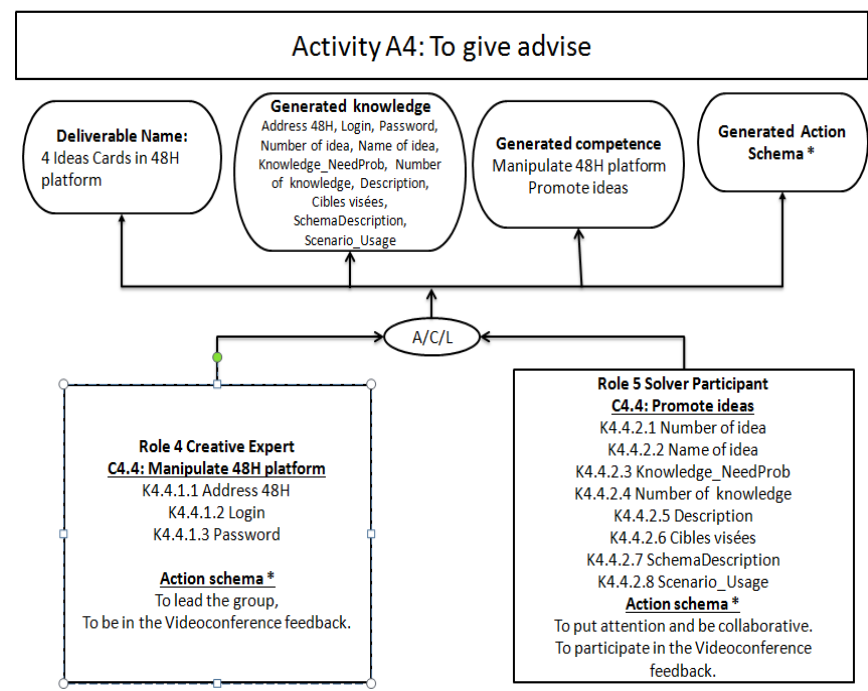

Figure 5. An Activity with Results Generated.

\section{The Role and Its Characteristics}

Knowledge Management is the result of Organizational Structure and Expertise Management. The role, table I below, has the description of the five essential characteristics in a CWS: Missions, Competences, Knowledge, Interactions and Responsibilities. The missions and goals are sharing by all roles to assure the interaction alliance and coalition among them.

\begin{tabular}{|l|l|}
\hline \multicolumn{1}{|c|}{ Role 4 Creative Expert } \\
\hline Organization & \multicolumn{1}{|c|}{ 48H of Creativity } \\
\hline Main missions & $\begin{array}{l}\text { Mission 1 } \\
\text { To invite stakeholders, universities, institutes and } \\
\text { investigation centers to collaborate in the event of } \\
\text { "48H", to add as many students as possible to the } \\
\text { event. } \\
\text { Mission 2 } \\
\text { To assure during 48 hours that students will apply a } \\
\text { collaborative and creative method. }\end{array}$ \\
\hline C2.1: To be assertive and explicit, to domain and \\
control groups, to be confident and calm. \\
C2.2: To be assertive and explicit. \\
C3: To create a report by group. \\
C4.1: To be assertive and explicit, to domain and \\
control groups, to be confident and calm. \\
C4.2: To domain and control groups, to be confident \\
and calm \\
C4.4: Manipulate 48H platform, C4.5 Promote Ideas \\
C5: To be loyal
\end{tabular}




\begin{tabular}{|l|l|}
\hline & Humans: \\
& Process 2, Activity 1-2 : Role 3/ Role 4/ Role 5 \\
& Process 3, Activity 1:Role 4/ Role 5 \\
& Process 4, Activity 1: Role 4/ Role 5; Activity 2: \\
& Role 2/ Role 4/ Role 5; Activity 3-4-5: Role 4/ Role \\
5 & Process 5, Activity 1: Role 4/ Role 5/Role 1 \\
& Interfaces: \\
& 48H platform \\
\hline Responsibilities & Process 2, Activity 1 : Consulted, Process 2, \\
& Activity 2: Consulted \\
& Process 3, Activity 1: Consulted \\
& Process 4, Activity 1-2-3-4-5: Consulted; \\
& Process 5, Activity 1: Responsible + Accounted \\
\hline
\end{tabular}

TABLE I. ROLE OF CREATIVE EXPERT

\section{Other CWS}

The creative workshop described in the literature [12],[13] are used in different domains like education, industry or entrepreneurial. CWS have three similar and important characteristics "Creative Techniques", "Role Solver-Participant" and "Role Creative Expert" and all integrate the concept of "creative thinking" to solve problems. In the table II is presented the comparison of three different creative workshops.

There are seven characteristics inside this comparative table showed above, clearly, $48 \mathrm{H}$ has a notable quantity of countries participants in contrast to the other CWS with just two countries; the roles created in $48 \mathrm{H}$ are specialized, but the mentors, in workshop III, applies a lot of creative technics, so the quantity of ideas is huge. In the other workshops (II educational and III entrepreneurial), the number of technics is minimum but the participant produce a very important quantity of ideas too. The workshops II and III are achieved by children who are by definition, more creative than adults.

The CWS " $48 \mathrm{H}$ " is given in 2 days, "Workshop in Creative Education for Students and Teachers" was given in one day, in contrast with the workshop "Creative Problem Solving Builds Entrepreneurial Mindset" that was given during four days in Fabretto's Education Center in San José de Cusmapa, Nicaragua. To ensure an enjoyable and active learning environment, a balanced combination of hands-on and creative problem solving activities, in addition to the introduction of important business concepts, were implemented. Because a successful entrepreneurial venture is usually initiated by an idea aiming to solve an important problem, understanding how to generate unique ideas, solving problems creatively, and overcoming the negative influences that obstruct creativity through various practical activities were the early steps of the concept development process and the central topics of the first day workshop. The second day was focused on the development of the components that make a business work properly using the business model. The last two days were centered on the financial aspects (revenue streams and cost structures) of the business model while continuing with more creative problem solving activities to supplement the discussion of the business components [13].

When an idea card is created, this is the result of the creative techniques which allow to participant to share their experiences and knowledge to generate a new concept; the knowledge shared and created linked to an idea has to be formalized in order to build intelligent creative support systems.

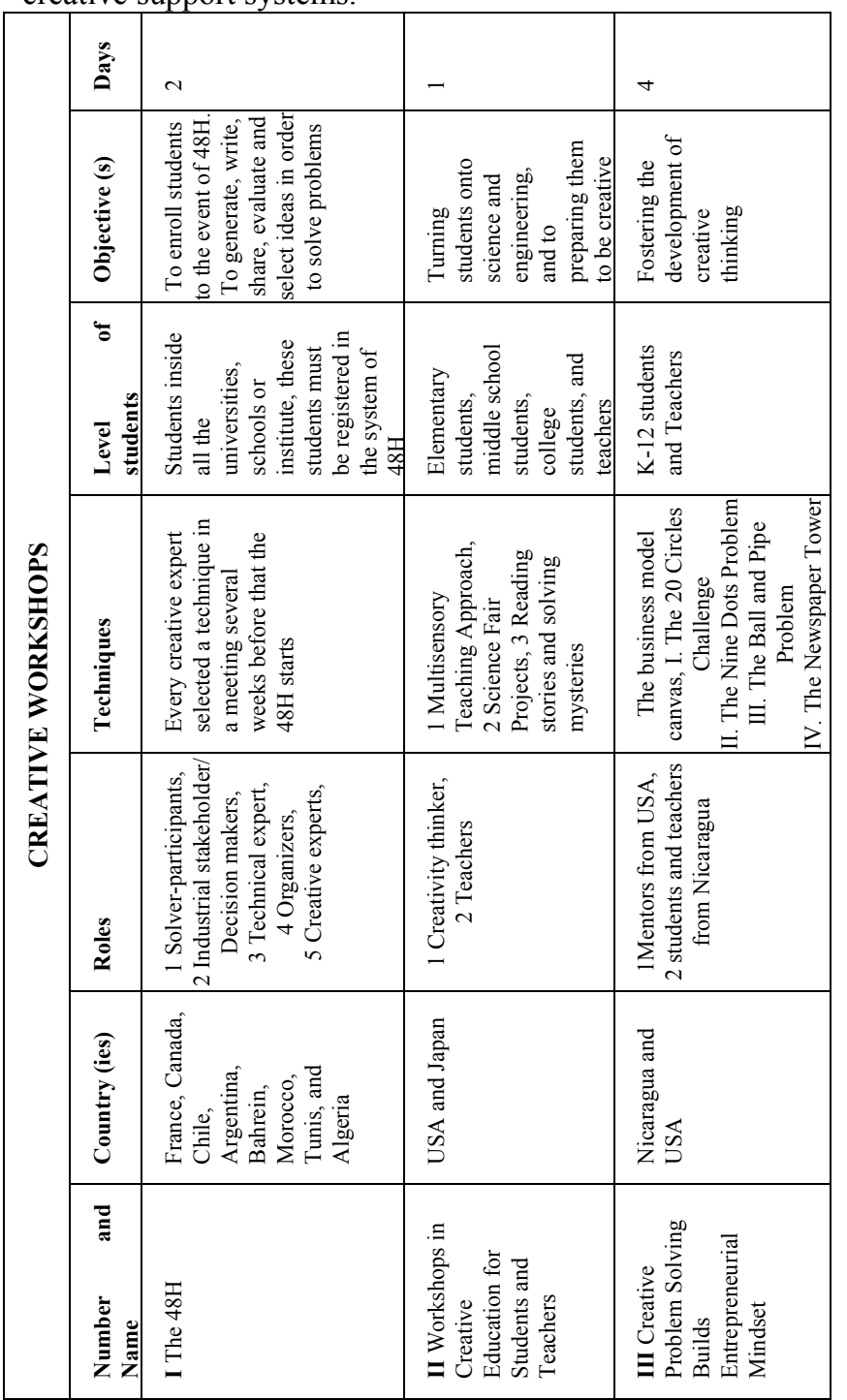

TABLE II. CHARACTERISTICS IN THREE CREATIVE WORKSHOPS.

Nowadays, organizations are conscious of the importance of their knowledge capital which constitutes a valuable source of wealth and a decisive competitive asset [14], according to that, the organization $48 \mathrm{H}$ agree and for this reason, we find knowledge at the same time understand the CWS.

The capitalization of the knowledge has four facets; one of the first tasks is to locate the crucial knowledge: it must be identified, located, characterized and classified. Next, it must be preserved, in other words conceptualized, formalized and conserved. Furthermore, it must be valueenhanced, i.e., put at the service of the development and expansion of the company. In other words, it must be accessed; disseminated, used more effectively, combined, and new knowledge must be created. Finally, it must be maintained - evaluated, made updateable, and improved in accordance with rules governing its confidentiality and security [15]; with respect to this, during the $48 \mathrm{H}$, knowledge is located like idea-cards and preserved by mean of the platform where solver participants can capture their idea-cards. The big quantity of idea cards can be observed, improved and evaluated, finally, all these idea 
cards and actions are stored and can be consulted by the people who are going to give an opinion about the solution of the problem.

Knowledge may be viewed from several perspectives (1) a state of mind, (2) an object, (3) a process, (4) a condition of having access to information, or (5) a capability [16]; in the $48 \mathrm{H}$, knowledge is an object, every object is an idea-card that is created, captured, modified and stored; moreover, knowledge is a capacity too, with this knowledge competences are created and problems are solved.

As a result of this, knowledge in $48 \mathrm{H}$ is modeled to understand how the participants create new concepts and ideas. This creative workshop is an organization where different participants with different roles (solverparticipants, creative expert, stakeholders, technical experts) work together to solve a problem by generating many ideas in a creative way; besides, in this organization participants will share their experiences and knowledge by interacting with each other.

\section{E. How to Identify/Analyze Knowledge during a Creativity Workshop}

The model KROM allows highlighting the roles, missions, goals, processes and activities in a creative workshop. During each activity, knowledge is required by role(s) but is generated too; in the table of role (Table 1 Role of creativity expert), knowledge and competences are required by the interaction of the agents with their responsibilities.

Knowledge has two resources, first, actors that assume a role, and second, processes that contain activities; after that, knowledge is obtained by mean of interaction of roles in the execution of an activity, the activity must follow a schema and an output or deliverable must be obtained. Moreover, knowledge is created too by mean of generation of ideas and Idea Cards with the purpose of "solving an industrial problem through to creativity and collaboration".

\section{F. Why Capitalize Knowledge}

We need models to get knowledge; the model KROM gives us the possibility to capitalize it by mean of idea-card and of course by mean of the different fields inside it. Every field of text has data and sometimes information which will be necessary to compare different idea-cards and to get the best idea-card. However, heterogeneous fields create a complex way to compare and to manipulate them, since text, image, sound fields with txt, jpg, mp3 or other formats could have different process.

To compare idea-cards, we need to separate the information of every field according to the type of data; we have to work with similar type of data. How to get the best idea-card?, the bases of this question are the industrial problem and the idea-card after that we have to interpret the information inside the idea-card according to the content inside the fields, in addition, we have to use annotation process to help to find the best idea-card.

The creativity workshop will evolve in the way: to write the text's fields, to draw and design the solution, and to produce sound about the idea-card. We think that part of this evolution we have to create tools to edit the fields in order to eliminate typographic and lexical errors, to create points, lines, curves to help in the solution's draw and to create and edit sound, these tools will make an easy formal way to specify the content or description of each idea-card (annotation) although the sound's topic and the draw are not a simple and trivial fields of the problem.

The way to annotate will make easy the way to compare idea-cards and the way to found the idea-card that makes the best solution to the problem however these processes has some semantics problems which must be defined and solved by mean of NLP Natural Language Processing; nevertheless, the annotation process will be different in text, image and sound since in the last two formats the annotation process could be defined before.

We have to annotate in the organizational context to explain where the ideas were created and use NLP annotation to explain and compare idea-cards in order to classify and to define the relevance of ideas according to an industrial problem. The way to annotate must be evolving every year in the creativity workshop $48 \mathrm{H}$ in order to obtain the best idea-card in an automatic process.

\section{G. Using Organizational Model to Capitalize Knowledge}

Fortunately, we have a creativity workshop $48 \mathrm{H}$ every year and we could use an organizational model to capitalize knowledge besides we could improve the annotation process and get better results in the comparative of idea-cards and to find the best idea-card that solves the industrial problem in an automatic way.

Everything has an evolution and the $48 \mathrm{H}$ is not the exception, thus we need to use models to understand the creativity workshops and get knowledge, perhaps the ideacard change or the condition in the workshop or the industrial purpose might change.

All the workshops have knowledge and we must use a model in order to understand them, besides, in the middle of an organization the knowledge will be capitalized. Using a model has other benefits such as understand the roles and the interaction among them, to know mission, objectives, processes and activities and perhaps other organizational models have better results to understand creativity workshops.

Finally, using a model is and will be a better way to obtain knowledge and understand any creativity workshop, moreover in all processes, activities, actions are better to use models to obtain good results or to do comparatives.

\section{CONCLUSION}

The event spends just two days; however, people from four continents, have been working all the year in order to obtain better and excellent results. The missions and goals were achieved by a collaborative team (students, teachers, industrial managers, technical experts). $48 \mathrm{H}$ is opened and perhaps next year other countries and industries could join to this CWS.

During a year, a lot of datas were captured, huge quantities of information are created, and according to the human interpretation of the information knowledge appears.

Finally, the model KROM was used and processes, activities, roles and concepts were clear and the skills and knowledge of people were highlighted. All industrial problems were solved during the $48 \mathrm{H}$ event of November 2017. 


\section{REFERENCES}

[1] and T. D. V. R. Reiter-Palmon, B. Wigert, "Team Creativity and Innovation: The Effect of Group Composition, Social Processes, and Cognition," in HandBook of Organizational Creativity, 2012, pp. 295-326.

[2] J. Girodon, D. Monticolo, E. Bonjour, and M. Perrier, "An organizational approach to designing an intelligent knowledge-based system: Application to the decision-making process in design projects," Adv. Eng. Informatics, vol. 29, no. 3, pp. 696-713, 2015.

[3] M. A. Boden, "Computer Models of Creativity," AI Mag., vol. 30, no. 3, p. 23, 2009.

[4] F. Damanpour and D. Aravind, "Organizational Structure and Innovation Revisited: From Organic To Ambidextrous Structure.," in HandBook of Organizational Creativity, 2012, pp. 483-512.

[5] T. Bhowmik, N. Niu, A. Mahmoud, and J. Savolainen, "Automated support for combinational creativity in requirements engineering," 2014 IEEE 22nd Int. Requir. Eng. Conf. RE 2014 - Proc., pp. 243-252, 2014.

[6] E. Benkhelifa, A. Tiwari, and A. Pipe, "Evolutionary design optimisation of a 32-step traffic lights controller," 2010 IEEE World Congr. Comput. Intell. WCCI 2010 - 2010 IEEE Congr. Evol. Comput. CEC 2010, pp. 1-5, 2010.

[7] F. J. Ruiz, C. Raya, A. S, and N. Agell, "A transformational creativity tool to support chocolate designers," Pattern Recognit. Lett., vol. 67, pp. 75-80, 2015.

[8] S. Acar and M. A. Runco, "Creative Abilities: Divergent Thinking," in HandBook of Organizational Creativity, Athens, GA, USA, 2012, pp. 115-139.
[9] J. S. Gero and M. Lou Maher, "Modeling Creativity and Knowledge-Based Creative Design."

[10] N. Khemiri, S. Sidhom, M. Ghenima, and H. Ben Ghezala, "properties and semantic relations."

[11] J. Girodon, D. Monticolo, E. Bonjour, and M. Perrier, "An organizational approach to designing an intelligent knowledge-based system: Application to the decision-making process in design projects," Adv. Eng. Informatics, vol. 29, no. 3, pp. 696-713, 2015.

[12] D. Barry, "Workshops in Creative Education for Students and Teachers in the United States and Japan," pp. 16-20, 2007.

[13] A. P. Camacho, A. Janowski, A. Konak, and S. Kulturel-Konak, "Creative problem solving builds entrepreneurial mindset," ISEC 2016 - Proc. 6th IEEE Integr. STEM Educ. Conf., pp. 65-70, 2016.

[14] M. Ben Hassen, M. Turki, and F. Gargouri, "Towards a Meta-model of the Organization' $s$ Processes modelling for Knowledge Localization," no. i.

[15] T. F. Group, "From Capitalizing on Company Knowledge to Knowledge Management," pp. 133.

[16] M. Leidner, Dorothy E and Alavi, "REVIEW : KNOWLEDGE MANAGEMENT AND KNOWLEDGE MANAGEMENT SYSTEMS :," vol. 25, no. 1, pp. 107-137, 2001. 